DIW BERLIN

Discussion Papers

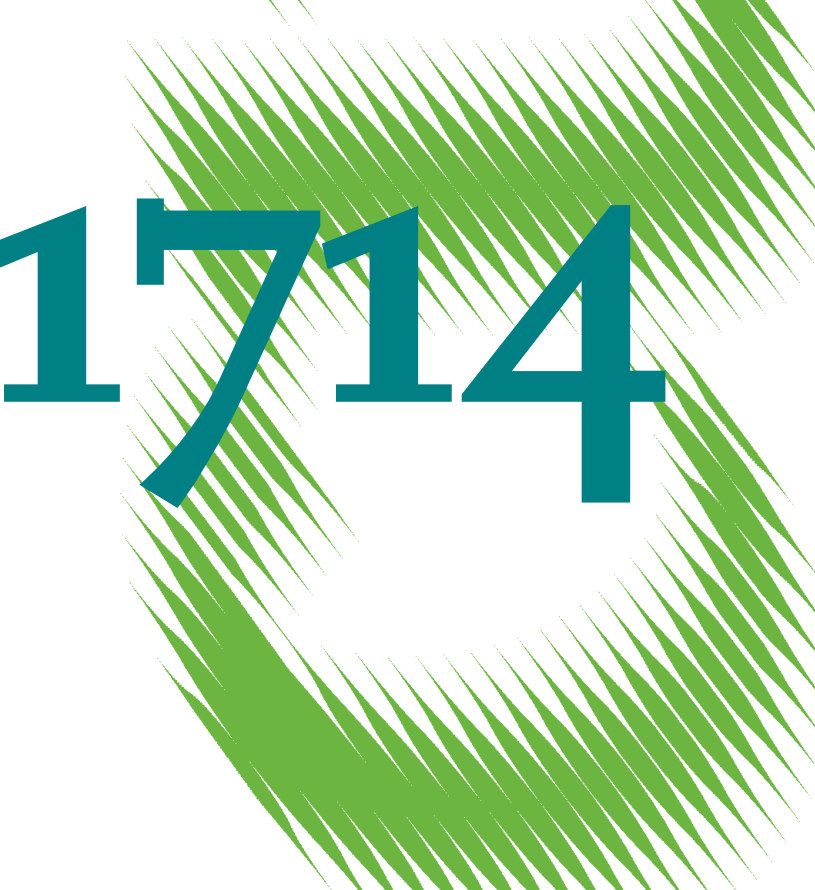

Project-Based Carbon Contracts: A Way to Finance Innovative Low-Carbon Investments 
Opinions expressed in this paper are those of the author(s) and do not necessarily reflect views of the institute.

IMPRESSUM

(C) DIW Berlin, 2017

DIW Berlin

German Institute for Economic Research

Mohrenstr. 58

10117 Berlin

Tel. +49 (30) $89789-0$

Fax +49 (30) $89789-200$

http://www.diw.de

ISSN electronic edition 1619-4535

Papers can be downloaded free of charge from the DIW Berlin website:

http://www.diw.de/discussionpapers

Discussion Papers of DIW Berlin are indexed in RePEc and SSRN:

http://ideas.repec.org/s/diw/diwwpp.html

http://www.ssrn.com/link/DIW-Berlin-German-Inst-Econ-Res.html 


\title{
Project-Based Carbon Contracts: A Way to Finance Innovative Low-Carbon Investments
}

\author{
Jörn C. Richstein ${ }^{*}$ \\ German Institute for Economic Research (DIW Berlin)
}

\begin{abstract}
Low and uncertain carbon prices are often stated as a major obstacle for industrial sector investments in technologies to deliver deep emissions reductions. Project-based carbon contracts underwritten by national governments could address regulatory risk, lower financing costs and strengthen incentives for emission reductions at investment and operation stage. In this paper design options for project-based carbon contracts are assessed using an analytical model capturing risk aversion of investors with a meanvariance utility function. The model is also used to assess how a combination with grant support for innovative projects can minimize overall costs of innovation policy. Savings in financing costs are quantified using a stylized project finance cash flow analysis.
\end{abstract}

Keywords: Emission trading systems, carbon contract, innovation support JEL Classifications: D81, Q48, Q54, Q55, Q58, O38

*JRichstein@diw.de 


\section{Introduction}

Reducing carbon emissions is an important policy objective, which requires action both from governments and private parties. Acemoglu et al. (2012) find that both carbon pricing, as well as research subsidies are necessary to direct innovation research into the direction of clean technologies. However, projects in capital intensive sectors often face a "valley of death" once they leave the pilot project phase (Nemet et al., 2016). This often occurs between the typical $R \& D$ funding, a classical push policy, and carbon pricing, a typical demand policy.

Two reasons that carbon prices itself have not been successful in contributing towards bridging the valley of death in Europe are the low prices of the EU ETS, as well as the associated price risk. These are not purely market driven, but consist also of a general credibility problem of governments and a time horizon problem of carbon markets (Helm and Hepburn, 2005). The general credibility problem is due to governments' incentive to renege on their policy position by for example, supplying additional allowances, react to failing international negotiations or not creating sufficient scarcity. The time horizon problem arises since the investment timescales for the assets and infrastructure needed for tackling climate change often exceed the commitment periods of the EU ETS. Helm and Hepburn (2005), propose to use carbon contracts to circumvent the problem by giving market participants certainty over the carbon price they face, and especially remove political risk, as well as signal their long-term willingness to a carbon market.

While carbon contracts may thus be an attractive way to lower financing costs of all mitigation projects, they seem to be especially well suited to address the challenges that those deep emissions reductions projects face. These projects are often beyond the typical scale of $R \& D$ funding, yet are not mature enough to be financed purely via an emissions trading scheme and the associated risks (von Stechow et al. (2011) and Groenenberg and de Coninck (2008) have indeed 
proposed to finance CCS power plants by carbon price guarantees). For the government, carbon contracts offer the additional attractive feature that as the carbon price rises the investment cost might be recuperated over time, especially since governments will usually apply lower discount rates than private firms.

In contrast to general carbon contracts outlined by Helm and Hepburn (2005), project-based carbon contracts for innovation funding would need to conform to design characteristics that set the right incentives while taking into account the requirements for innovation support ${ }^{1}$. First, a project-based carbon contract would need to have its volume dynamically allocated to the actual delivered emissions reductions and not have take-or-pay clauses. Otherwise, companies would risk to be stranded with a contract that may be priced below market prices. This would hamper the incentives to invest in highly innovative projects with risks of technological failure. Second, contracts would need to be specifically bound to emissions reductions delivered by one specific project, as otherwise emission reductions could be delivered by a portfolio of incremental technological options without achieving the innovation support (for example by being split and sold on to third parties).

We therefore propose that carbon contracts could be used specifically to support the scaling up of innovative deep emission reduction projects. Such carbon contracts could also be used in conjunction with traditional direct funding of innovation projects.

This paper will first discuss general design considerations for the introduction of project-based carbon contracts. Then we show the principle way that carbon contracts lower the necessary funding for deep emission reduction projects, using a simple analytical model of a risk averse investor and a government trying to minimize the funding level, while ensuring that the investment is being carried out. Finally, a stylized project finance cash flow model is used to

\footnotetext{
${ }^{1}$ General carbon contracts may follow the same design, however a higher emphasis on setting incentives for short-term efficiency, may lead to different design choices, such as making contracts tradeable and including take-or-pay clauses to ensure the delivery of emissions reductions
} 
quantify the effect on financing costs in a simple example case.

\section{Design considerations}

For establishing carbon contracts, several design elements need to be considered such as the form of the contract, the scope and eligibility of the contract, the volume of the contract and the price of the contract. Where carbon policies exist, investors face uncertainties regarding the development of carbon prices. This has been especially true for price developments within the European Emissions Trading System, but, due to policy uncertainty can also be applicable to carbon taxes or price floors. Where such systems are in place, the carbon contract could be established as a carbon contract for difference (CCfD) on the existing carbon price, as otherwise the effective carbon price level would be affected but not its volatility. The contract pays out the difference between the carbon price and the agreed strike price, thus effectively ensuring a guaranteed carbon price ${ }^{2}$. A suitable reference price accessible to market participants should be chosen to minimize the basis risk for investors. In the case of the EU ETS and other emissions trading systems, this role could be played by the average price of monthly EU allowance auctions. In the European context national governments could be the counter parties to the carbon contract, but may act in a coalition or coordinate on the carbon contract price. The legal implementation would need to be tailored to the budget law of the given country.

Instead of implementing project-based carbon contracts for difference, governments could also award put options and EU allowances (the right to sell a carbon allowance at a given price), as suggested by Ismer and Neuhoff (2006). In addition to insurance for individual projects, if sufficient put options are issued, this would create a price floor with allowances being returned to government in the case of excess supply. Given the financial commitment, governments would

\footnotetext{
${ }^{2}$ This holds as long as the free allocation of allowances corresponds to the carbon cost pass through level to the end product price.
} 
strive to increase stringency from the beginning, further increasing the commitment. However, if only some EU governments were to issue such put options it is unclear how this would impact the incentives for other EU member states to contribute to further development of EU ETS and how this in turn impacts the liabilities. In contrast, project-based carbon contracts limit the exposure to individual projects and allow the government to capture the upside of carbon price development in case it increases.

If used as an innovation support tool with a higher carbon price than the current market price, targeted at investments in new production processes, practices or substitution materials, each carbon contract should be linked to a specific investment, as otherwise it would lead to windfall profits by being fulfilled by a portfolio of incremental emissions reductions or traded to other market participants, as current incremental abatement options will usually have lower costs. In the European context it needs to be considered that a carbon strike price that exceeds the expected carbon price during project duration could be considered as state aid. Such state aid would need to be justified for environmental or for innovation reasons.

The volume of the contract reflects the volume of emissions reductions of the innovative project relative to the traditional technology to lower the carbon price risk for investors (as otherwise they would have a potentially unhedged position on the carbon market), as well as to maintain the incentives at all times to lower emission levels. The emissions reductions can be determined by multiplying the best-available technology (BAT) benchmark at the time of investment with the production volumes of the given process (also in case of substitution materials) and substract the reported yearly emissions. In existing carbon pricing schemes monitoring mechanisms for compliance exist and can be utilized to keep administrative costs of carbon contracts at a low level.

The price of the carbon contracts could either be determined by the policy maker or in a tender (as suggested by Helm and Hepburn, 2005). As for the 
initial years it is likely that even in the presence of project-based carbon contracts, additional innovation funding, for example via grants, would be necessary to cover the learning costs and thus the coordination of different instruments will be important.

Therefore a practical way is for governments to announce a carbon contract price that is accessible for deep emission reduction projects, and differentiate the grant level using for example tenders. A set of factors will influence the balance between the carbon price level in the contracts for difference and the grant level. As will be shown later in this paper, if no efficiency losses exist for up-front grants, in order to minimize the funding level for governments, a combination of the two would achieve the lowest absolute funding levels, if the incremental capital costs are covered by grants and the incremental operational costs by carbon contracts. However, other considerations could play a role as well. Carbon contracts allow the spreading of public funding to future years, which is an argument for a higher share of funding via carbon contracts. Furthermore, if no clawback clauses exist for grants, a higher share of grants would lower the incentive for companies to succeed. On the other hand, a higher share of carbon contract funding or clawback clauses might make them more risk averse in their technological choices, when society might benefit more from a portfolio of long-shot technologies and thus a shifting of technological risks to the public. The price level of such carbon contracts may also serve as guide posts for the carbon market. If the carbon contract price only reflects the incremental variable cost, as the fixed incremental costs are funded separately, this may send the wrong signal to market parties and the policy process ${ }^{3}$.

\footnotetext{
${ }^{3}$ But could be averted if both are published separately, or only a joint abatement cost level computed over the fixed and variable component is published
} 


\section{Analytical model}

We develop a simple analytical model of a firm with an innovative carbon reduction project that reduces emissions of a given product (for example a material, such as steel or cement), as well as a government that may choose to support the project with a carbon contract at price $p_{c c}$ or a grant $F$ (fixed ex-ante funding level). The goal of the government is to minimize the public expenditure on the project (the expected price difference between the carbon contract price and the $\mathrm{CO}_{2}$ market price $\left.p_{\mathrm{CO}}\right)$, under the condition that the investment is taking place, i.e. that the expected utility (EU) from the stochastic profit $\pi$ of the investment for the firm is greater than zero.

$$
\begin{aligned}
& \min _{p_{c c}, F}\left[\mathbb{E}\left[q\left(p_{c c}-p_{C O 2}\right)\right]+F\right] \\
& \text { s.t. } \quad \mathrm{EU}(\pi) \geq 0
\end{aligned}
$$

We assume that the firm sells in a market that is so far dominated by a price-setting dirty baseline technology with operational costs $c_{o p}$. We assume that in order to reduce emissions (with a remaining emission level of $\alpha$ ) the company has incremental operational costs $\Delta c_{o p}$ above the operational costs of the baseline technology. We also assume that the company needs to make an additional investment of $\Delta c_{i n v}$ for the project. Under an emissions trading system (without any other policy support) the profit for an innovative project is ${ }^{4}$ :

$$
\pi=\left(p_{g}+p_{\mathrm{CO} 2}\right) q-\left(c_{o p}+\Delta c_{o p}+\alpha p_{\mathrm{CO} 2}\right) q-\Delta c_{i n v}
$$

Where stochastic profit of the company is denoted with $\pi, p_{g}$ is the price of the good in question (in absence of a $\mathrm{CO}_{2}$ price), $p_{\mathrm{CO} 2}$ is the stochastic $\mathrm{CO}_{2}$ price, $q$ is the produced quantity (stochastic to represent the risk of technological

\footnotetext{
${ }^{4}$ For simplicity we value the project on its own, not including the prospective value it generates for future projects by learning-by-doing and in terms of intellectual property.
} 
failure and/or market quantity risk). For simplicity we assume that the emission intensity of the price setting base-line technology is 1 and that there is a complete pass-through of $\mathrm{CO}_{2}$ costs to the price, therefore resulting in a market price of the good of $p_{g}+p_{\mathrm{CO} 2}$.

As the carbon cost for an innovative emission-saving technology increases only with a fraction of the carbon price $\alpha p_{\mathrm{CO} 2}$, the profit of the clean company increases with the carbon price.

We assume that the firm operates in a competitive market, which is dominated baseline technology, and that the price of the good is marginal cost of production: $p_{g}=c_{o p}$. If we substitute this in the profit equation, it simplifies the stochastic profit for the clean technology to:

$$
\pi=p_{\mathrm{CO} 2} q-\left(\Delta c_{o p}+\alpha p_{\mathrm{CO} 2}\right) q-\Delta c_{i n v}
$$

In case the carbon price level by itself is insufficient to stimulate investment in an innovative project, the government may choose to offer a carbon contract above the expected market to support innovation as well as a separate grant $F$. We assume that the carbon contract is implemented as a contract for difference on the current carbon price (CCfD), and that the quantity of contracts is dynamically allocated according to emissions reductions below the benchmark emission level of the base-line technology.

If a carbon contract for difference at a price level $p_{c c}$ (scaling with production $q)$ and a grant at level $F$ with an inefficiency factor $g(g>1)$ is given to a company, the stochastic profit changes to:

$$
\begin{aligned}
\pi & =p_{\mathrm{CO} 2} q-\left(\Delta c_{o p}+\alpha p_{C O 2}\right) q-\Delta c_{i n v}+(1-\alpha) q\left(p_{c c}-p_{C O 2}\right)+F \\
& =\left((1-\alpha) p_{c c}+\alpha p_{C O 2}\right) q-\left(\Delta c_{o p}+\alpha p_{C O 2}\right) q-\Delta c_{i n v}+F \\
& =\left((1-\alpha) p_{c c}-\Delta c_{o p}\right) q-\Delta c_{i n v}+\frac{F}{g}
\end{aligned}
$$


As can be seen, the carbon contract removes any $\mathrm{CO}_{2}$ price uncertainty from the project. In order to simplify the analysis, we look at the case of a carbon contract by itself, and funding distribution between the contract for difference and a direct innovation funding separately.

\subsection{A carbon contract by itself}

In a first step, we analyse the situation of the government only providing support via a carbon contract (i.e. $F=0$ ) under certainty. In this case there is only a single variable, the carbon contract price, for which we can solve directly:

$$
\begin{aligned}
\pi & =\left((1-\alpha) p_{c c}-\Delta c_{o p}\right) q-\Delta c_{i n v} \geq 0 \\
\Rightarrow & p_{c c}^{*} \geq \frac{\Delta c_{o p}+\frac{\Delta c_{i n v}}{q}}{1-\alpha}
\end{aligned}
$$

The carbon price thus needs to be at least as high to cover the incremental operational cost, as well as the incremental specific investment cost divided by the specific emissions reductions.

If there is uncertainty and we assume that the firm is risk averse and has a mean-variance utility function of $E U(\pi)=\mathbb{E}[\pi]-\frac{\lambda}{2} \operatorname{Var}[\pi]$ (equivalent to assuming normal distribution for the stochastic variable and an exponential utility function), we can again solve for the carbon contract price necessary to just realize the investment (assuming $\alpha=0$ for simplicity):

$$
\begin{aligned}
& E U(\pi)=\mathbb{E}\left[\left(p_{c c}-\Delta c_{o p}\right) q-\Delta c_{i n v}\right]-\frac{\lambda}{2} \operatorname{Var}\left[\left(p_{c c}-\Delta c_{o p}\right) q-\Delta c_{i n v}\right] \geq 0 \\
& \Rightarrow\left(p_{c c}-\Delta c_{o p}\right) \mathbb{E}[q]-\Delta c_{i n v}-\frac{\lambda}{2} \operatorname{Var}[q]\left(p_{c c}-\Delta c_{o p}\right)^{2} \geq 0 \\
& \Rightarrow p_{c c}^{*} \geq \Delta c_{o p}+\frac{q-\sqrt{\left(\mathbb{E}[q]^{2}-2 \lambda \Delta c_{i n v} \operatorname{Var}[q]\right)}}{\lambda \operatorname{Var}[q]}
\end{aligned}
$$

As compared to the certain case, the necessary carbon contract price to realize 
the investment is the sum of the specific incremental costs and an additional risk premium growing with the uncertainty (variance) ${ }^{5}$ of the production volumes of the good, the incremental investment costs and the risk aversion of the investor. Put in different terms, the risk premium rises the more the incremental cost of the new technology is determined by incremental investment costs and not by incremental operational costs, and the higher the uncertainty is regarding the production volumes (which is used as a proxy for market and technological risk here).

\subsection{Carbon contracts or fixed funding}

The government can choose to either provide a fixed funding level or a carbon contract for difference. Under certainty of the quantity and no inefficiency in providing grants these options are equivalent for the company investing, as it would be receiving a certain carbon price and a known quantity of production ${ }^{6}$. If we relax the assumption that the quantity sold is certain (either due to market risk, or technological risk of producing at the planned output level), this is not necessarily true anymore. We thus investigate the effect of the funding distribution between a fixed funding level and a CCfD. To simplify the analysis, we assume that the project is fully decarbonized $(\alpha=0)$. We again assume a mean-variance utility function for the private actor, as well as independent normal distributions.

$$
\min _{p_{c c}, F}\left[\mathbb{E}\left[q\left(p_{c c}-p_{C O 2}\right]+F\right]=\min _{p_{c c}, F}\left[\left(p_{c c}-\mathbb{E}\left[p_{C O 2}\right]\right) \mathbb{E}[q]+F\right]\right.
$$

s.t. $E U(\pi) \geq 0$

\footnotetext{
${ }^{5}$ The derivative of $\frac{d p_{c c}}{d \operatorname{Var}[q]}=\frac{\Delta c_{o p} \lambda+\frac{\Delta c_{i n v} \lambda}{\sqrt{\mathbb{E}[q]^{2}-2 \Delta c_{i n v} \lambda \operatorname{Var}[q]}}}{\lambda \operatorname{Var}[q]}-\frac{\mathbb{E}[q]+\Delta c_{o p} \lambda \operatorname{Var}[q]-\sqrt{\mathbb{E}[q]^{2}-2 \Delta c_{i n v} \lambda \operatorname{Var}[q]}}{\lambda \operatorname{Var}[q]^{2}}>$ 0 , as long as $2 \Delta c_{i n v} \operatorname{Var}(q) \lambda<\mathbb{E}[q]^{2}$, which is a necessary condition for the model to be in its range of feasible solutions.

${ }^{6}$ Ignoring the timing of payments and potential consequences, such as discounting and other uncertainties.
} 
Using the mean-variance utility function, the profitability condition of the firm can be reformulated to:

$$
\begin{aligned}
& \mathbb{E}[\pi]-\frac{\lambda}{2} \operatorname{Var}[\pi] \geq 0, \quad \text { with } \pi=\left(p_{c c}-\Delta c_{o p}\right) q-\Delta c_{i n v}+\frac{F}{g} \\
& \Rightarrow\left(p_{c c}-c_{o p}\right) \mathbb{E}[q]-\Delta c_{i n v}+\frac{F}{g}-\frac{\lambda}{2}\left(p_{c c}-c_{o p}\right)^{2} \operatorname{Var}[q] \geq 0
\end{aligned}
$$

The associated Langragian can be formulated as:

$$
\begin{aligned}
& \min _{p_{c c}, F, \omega} \mathcal{L}= \\
& \min _{p_{c c}, F, \omega}\left(p_{c c}-\mathbb{E}\left[p_{C O 2}\right]\right) \mathbb{E}[q]+F+\omega\left(c_{i n v}-\frac{F}{g}-\left(p_{c c}-c_{o p}\right) \mathbb{E}[q]+\frac{\lambda}{2}\left(p_{c c}-c_{o p}\right)^{2} \operatorname{Var}[q]\right)
\end{aligned}
$$

Deriving the Langragian, we arrive at the first order conditions:

$$
\begin{gathered}
\frac{\partial \mathcal{L}}{\partial p_{c c}}=\mathbb{E}[q]+\omega\left(\lambda\left(-c_{o p}+p_{c c}\right) \operatorname{Var}[q]-\mathbb{E}[q]\right)=0 \\
\frac{\partial \mathcal{L}}{\partial F}=1-\frac{\omega}{g}=0 \\
\frac{\partial \mathcal{L}}{\partial \omega}=\left(c_{i n v}-\frac{F}{g}-\left(p_{c c}-c_{o p}\right) \mathbb{E}[q]+\frac{\lambda}{2}\left(p_{c c}-c_{o p}\right)^{2} \operatorname{Var}[q]\right) \geq 0 \quad \perp \quad \omega \geq 0 \\
p_{c c} \geq 0, \quad F \geq 0
\end{gathered}
$$

The solution solving these first order conditions is:

$$
F=g \Delta c_{i n v}-\frac{\left(g^{2}-1\right) \mathbb{E}[q]^{2}}{2 g \lambda \operatorname{Var}[q]}, \quad p_{c c}=\Delta c_{o p}+\frac{(g-1) \mathbb{E}[q]}{g \lambda \operatorname{Var}[q]}, \quad, \omega=g
$$



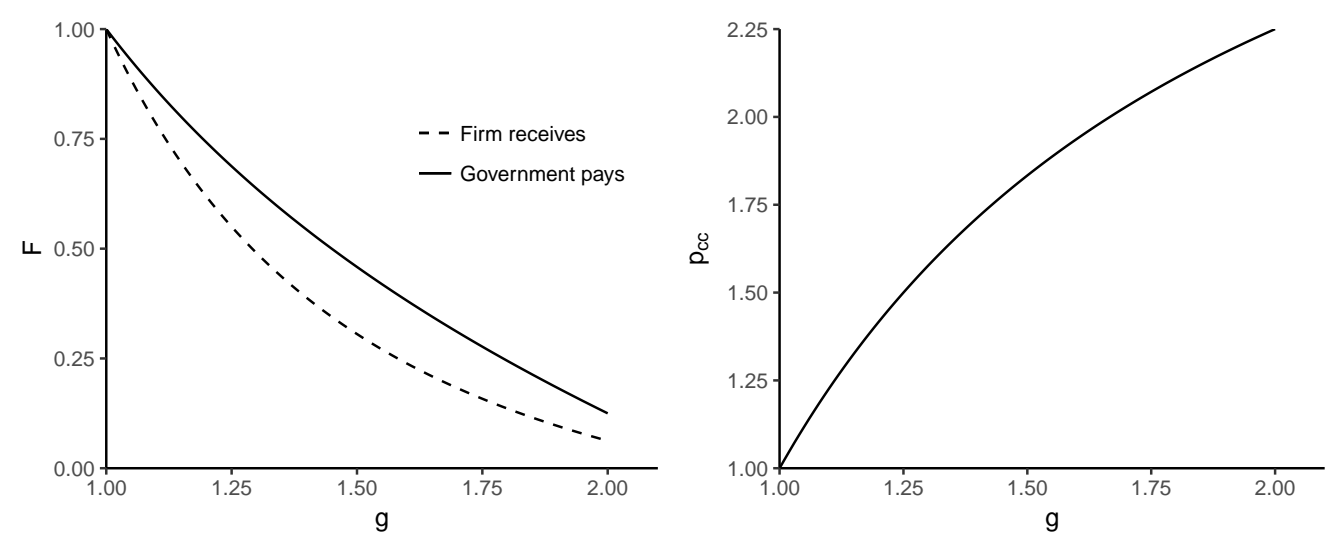

(a) Effect of the inefficiency $g$ on the optimal (b) Effect of the inefficiency $g$ on the optimal grant level $F$ carbon contract price $p_{c c}$

Figure 1: Example parameterisation of the model with $\Delta c_{o p}=$ $1, \Delta c_{i n v}=1, \operatorname{Var}[q]=0.2, \mathbb{E}[q]=1, \lambda=2$.

As there is only one binding constraint $(\omega>0)$, this solution is also the optimal solution to the minimisation problem of the government. If there is no inefficiency to the grant (i.e. $g=1$ ), the solution simplifies to:

$$
F=\Delta c_{i n v}, \quad p_{c c}=\Delta c_{o p}, \quad, \omega=1
$$

In case there are no inefficiencies in providing grants the expected costs for funding the innovative project are thus minimized if the carbon contract price is equal to the incremental operational costs, and the fixed funding is equal to the incremental investment costs. This is intuitively sensible, as the dynamically allocated part of the innovation funding (the carbon contract) is linked to the incremental variable costs and the fixed part of the incremental cost linked to the fixed funding level.

If, however, there is some inefficiency to providing grants (for example due to lessened incentives for companies to succeed or advantages for the public of providing funding over time instead of ex-ante), as the inefficiency rises in the optimal solution, more and more funding is shifted to carbon contracts ${ }^{7}$, as can

\footnotetext{
${ }^{7}$ This is generally true as, $\frac{d F}{d g}<0, \frac{d p}{d g}>0$ given the existing assumptions of our model.
} 
also be seen in the example parametrisation of the model in Figure 1.

\section{Example quantification of financing costs}

In this section we show a more practice oriented example of how carbon contracts can lower financing costs, using a simplified, project-finance based calculation. For this we discuss the illustrative case of a greenfield investment in a conventional steel making technology, as well as a generic, low-carbon alternative. The data for the conventional steel making technologies fall into the range for greenfield investments given in the BF-BOF route described by Wörtler et al. (2013) and Fischedick et al. (2014), but are used here for illustrative purposes only. It should be noted that at current steel prices greenfield investments in Europe are not profitable and the price ranges given here are thus significantly above current market prices of steel.

Based on technological cost assumptions and a debt level of $40 \%$, we determine a lower steel price at which the debt payments could just be served, and an upper steel price at which the investment would be profitable. Given this uncertainty regarding steel prices, we determine the necessary lower carbon price to let the low-carbon technology serve its debt level, and a necessary carbon price for it to be profitable. Following that we show that with a carbon contract, which gives a guaranteed carbon price, higher debt ratios and correspondingly decreased financing cost can be achieved, leading to a lower necessary carbon price level to make the low-carbon technology competitive. The result of the analysis is graphically depicted in Figure 2, and will be detailed in the following.

As a base case we take the investment in a conventional steel plant, with

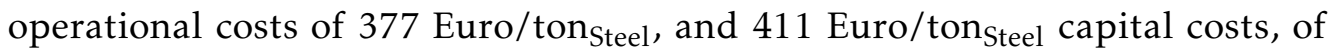
which 101 Euro/tonSteel go to serving debt payments (at a typical 40\% level of debt in the steel sector). This gives a range of steel prices from 481 Euros/Steel at which debt payments can just be served, to 789 Euros/ton Steel $_{\text {at }}$ which price 


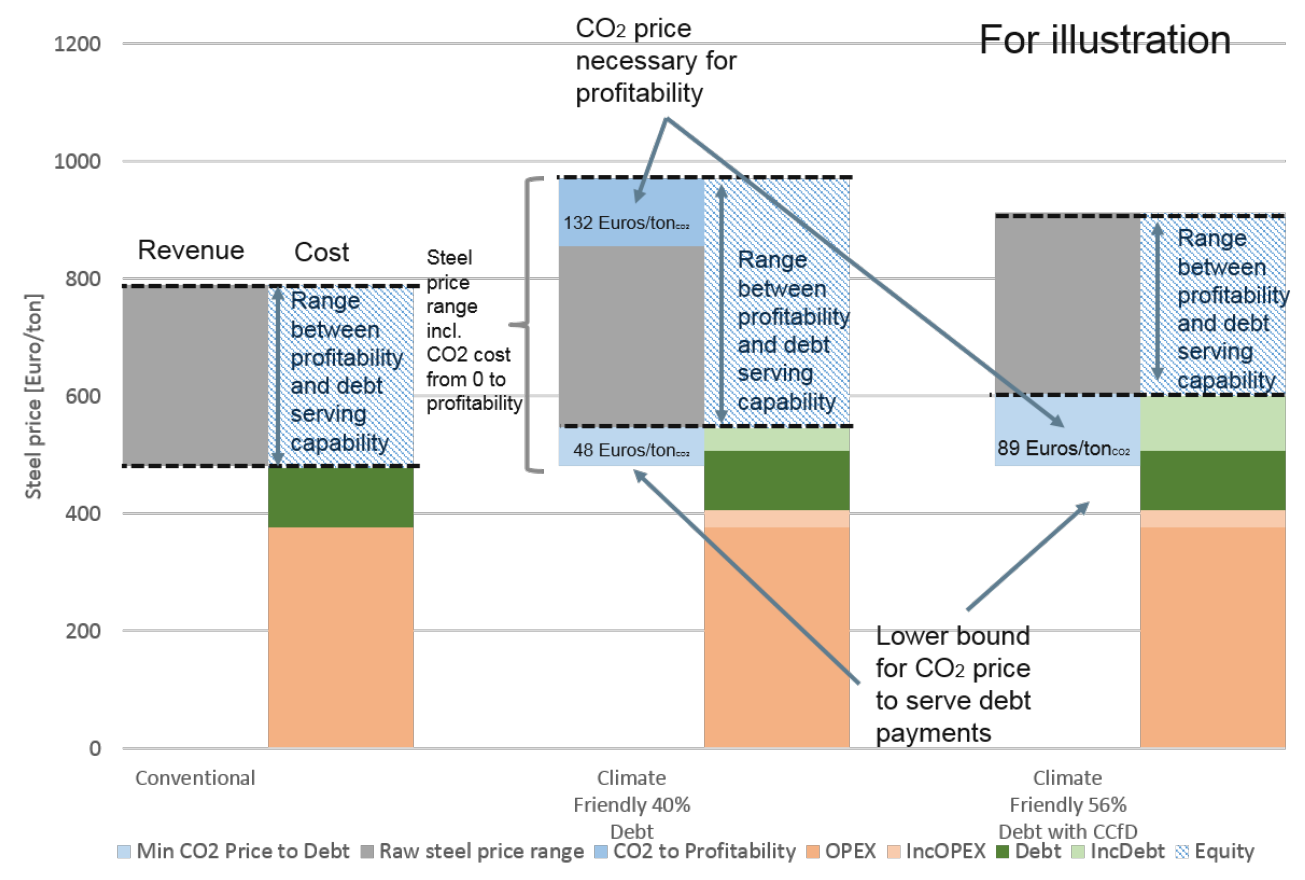

Figure 2: Static cash-flow comparison of conventional and low-carbon steel alternatives

the investment would be profitable. For the following comparison with the lowcarbon alternative, we assume that emissions allowances are freely allocated, but can be sold at a profit if emissions reductions are achieved. We assume a relatively moderate operational cost increase of $7.6 \%$ to 406.5 Euro/tonSteel, and an overnight investment cost increase of $37.3 \%$ over the baseline technology. If the investment has the same debt level of $40 \%$, this leads to capital expenditure of 565 Euro/ton Steel $_{\text {of which } 138 \text { Euro/ton }}$ Steel are interest payments. This would necessitate a lower expected $\mathrm{CO}_{2}$ price of 48 Euros/ton $\mathrm{CO}_{2}$ for the project to serve its debt. In order to be profitable, the project would need to expect a

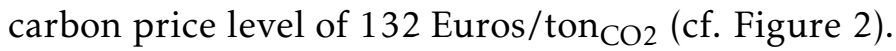

If the project entered into a CCfD at a carbon price level of 89 Euros/ton $\mathrm{CO}_{2}$, the debt ratio could be increased to $56 \%$, while the project would still be able to serve its debt payments of 195 Euro/tonSteel. Due to the lower financing cost, the overall steel production cost would fall from 972 Euro/ton Steel $_{10} 912$ 


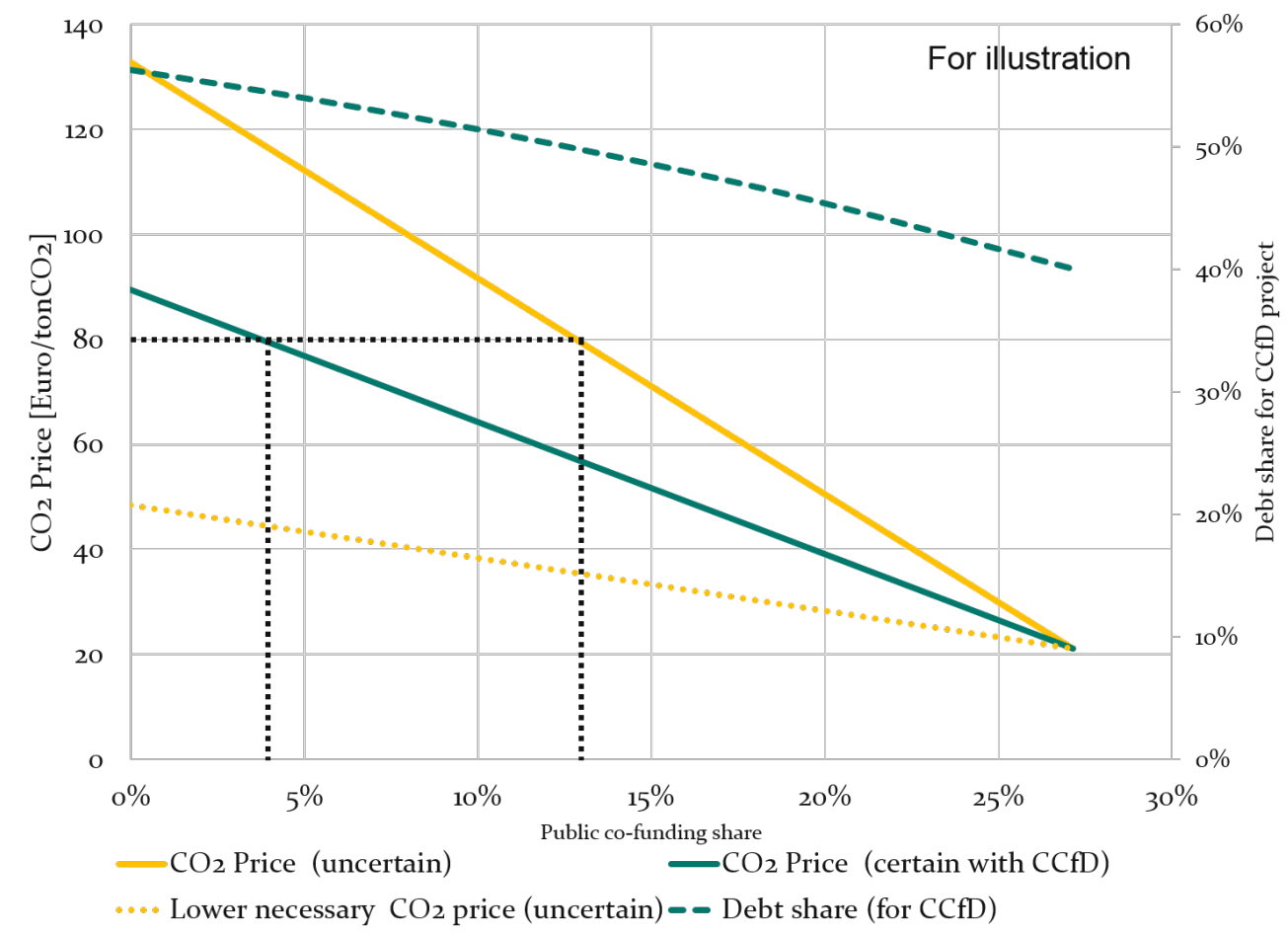

Figure 3: Effect of carbon contracts on public co-funding shares for low-carbon steel example case

Euro/ton Steel $_{\text {. }}$

If carbon contracts are combined with public grants, they can significantly decrease the necessary funding levels to realize innovative projects. Figure 3 depicts the necessary public co-funding and $\mathrm{CO}_{2}$ price combinations necessary to make investments in the low-carbon alternative profitable. The case discussed so far corresponds to no public co-funding. As can be seen, at a given carbon price level, the share of public grants in overall investment can be significantly reduced, if a certain carbon price via a CCfD can be supplied - at a carbon price level of 80 Euro/ton $\mathrm{CO}_{2}$ from $12.8 \%$ public co-funding to $3.7 \%$.

\section{Conclusion}

This paper discusses project-based carbon contracts as a potential way for governments to support innovative low-carbon investments, for example to support 
deep emissions reductions projects in the industrial sector. These have several advantages, such as lowering policy and carbon price uncertainty, setting incentives for project success and the opportunity for governments to recuperate their costs, when the carbon price rises.

First, design options for carbon contracts issued by governments are discussed, especially the direct linkage to a project through project specific carbon contracts and to EU ETS carbon prices with a contracts for difference structure. Several governments could coordinate on a price level corresponding to the longterm ambition of carbon reduction targets, in order to present a standardized framework. Existing benchmarks could be used, and the carbon contracts could built on monitoring, reporting and verification mechanisms in existing carbon markets to keep administrative discretion and costs low. Where project-based carbon contracts are targeted at innovative projects, this offers the opportunity to use the award process for the grant to determine qualification for the projectbased carbon contracts. This would ensure that contracts would be provided to projects in line with the long-term climate reduction targets. A competitive grant award process (e.g. tender) could also ensure that overall public support is minimized while maintaining a common reference price for all project-based carbon contracts.

Second, an analytical model capturing risk-aversion of investors by applying a mean-variance utility function was developed which is used to assess the trade-off between funding innovation projects via grants or carbon contracts. It shows that risk, and thus necessary funding is minimised when a mix of grants and carbon contracts corresponding to respectively incremental investment and operational cost is used, as this removes carbon price uncertainty (regulatory or price based) and lowers the variability of income streams. However, other factors such as the lessened incentives for companies to succeed under the grants or advantages for the public of providing funding over time instead of ex-ante are important when considering the distribution of funding via grants 
or carbon contracts. The higher the inefficiency of grants (for example due to aforementioned reasons), the more funding should take place in the form of carbon contracts.

Third, a quantitative cash-flow model is used to quantify potential savings in innovation funding if carbon contracts are used. It shows that carbon contracts with separate innovation grants could considerably reduce the overall funding level necessary, by reducing the volatility of cash flows streams, and thus enabling access to higher levels of debt finance, which typically requires lower rates of interest than equity. This reduces overall financing costs and would help address existing constraints on innovation funds.

\section{Acknowledgements}

The author is grateful for financial support from the German Federal Ministry for Economic Affairs and Energy under grant number 03MAP316. The views and opinions expressed in this publication do not necessarily reflect the views of the Ministry. The author is also grateful for discussions with and comments by Karsten Neuhoff, Nils May, Vera Zipperer as well as Cameron Hepburn and other participants at the FSR Climate Annual Conference 2017.

\section{References}

Acemoglu, D., Aghion, P., Bursztyn, L., and Hemous, D. (2012). The environment and directed technical change. American Economic Review, 102(1):131-66.

Fischedick, M., Marzinkowski, J., Winzer, P., and Weigel, M. (2014). Technoeconomic evaluation of innovative steel production technologies. Journal of Cleaner Production, 84(Supplement C):563 - 580. Special Volume: The sustainability agenda of the minerals and energy supply and demand network: 
an integrative analysis of ecological, ethical, economic, and technological dimensions.

Groenenberg, H. and de Coninck, H. (2008). Effective EU and member state policies for stimulating CCS. International Journal of Greenhouse Gas Control, $2(4): 653-664$.

Helm, D. and Hepburn, C. (2005). Carbon contracts and energy policy: an outline proposal. Working Paper, University of Oxford.

Nemet, G., Kraus, M., and Zipperer, V. (2016). The valley of death, the technology pork barrel, and public support for large demonstration projects. Discussion Papers of DIW Berlin 1601, DIW Berlin, German Institute for Economic Research.

von Stechow, C., Watson, J., and Praetorius, B. (2011). Policy incentives for carbon capture and storage technologies in europe: A qualitative multi-criteria analysis. Global Environmental Change, 21(2):346 - 357. Special Issue on The Politics and Policy of Carbon Capture and Storage.

Wörtler, M., Schuler, F., Voigt, N., Schmidt, T., Dahlmann, P., Lüngen, H., and Ghenda, J.-T. (2013). Steel's contribution to a low carbon Europe 2050. Technical and economic analysis of the sectors $\mathrm{CO} 2$ abatement potential. Technical report, The Boston Consulting Group. 